\title{
The Non-isothermal Kinetic Analysis of Thermal Decomposition of $\operatorname{Mg}(\mathbf{O H})_{2}$
}

\author{
YUE, Lin-Hai $\quad$ JIN, Da-Lai $\quad$ LU, De-Yi $\quad$ XU, Zhu-De \\ (Department of Chemistry, Zhejiang University, Hangzhou 310027; ${ }^{1}$ College of Chemical Engineering and Materials Science, \\ Zhejiang Industrial University, Hangzhou 310014)
}

\begin{abstract}
The thermal decomposition kinetics of magnesium hydroxide was investigated using the non-isothermal approach. It was proved that the mechanism of this reaction corresponded to the nucleation and growth mechanism $\mathrm{A}$, but changed from $\mathrm{A}_{2}$ to $\mathrm{A}_{1.5}$ with rising heating rate. The activation energy of decomposition, both estimated by the non-mechanismic Kinssinger equation and calculated by a numerical regression method according to the deduced mechanism, was around $148 \mathrm{~kJ} \cdot \mathrm{mol}^{-1}$. Further investigation revealed that water vapor had an extraordinarily significant effect on the thermal decomposition mechanism of magnesium hydroxide.
\end{abstract}

Keywords: Magnesium hydroxide, Thermal decomposition, Non-isothermal kinetics

Magnesium hydroxide is one of the most widely used inorganic materials that has many industrial applications such as utilized in foodstuff ${ }^{[1]}$, water treating ${ }^{[2]}$, smoke letting ${ }^{[3]}$, and desulphurization $^{[4]}$. Recently, much interest has been attracted into its application as a flame retardant ${ }^{[5-6]}$. Many reports have described magnesium hydroxide as a new inorganic retardant which is more effective and environment friendly than the widely used traditional inorganic retardant-aluminium hydroxide ${ }^{[5-8]}$. The capability of its fire-preventing is usually attributed to the absorption of heat during its thermal decomposition when the produced water molecule turns from liquid state into gas phase. Therefore it is of great significance to investigate the thermal decomposition kinetics of $\mathrm{Mg}(\mathrm{OH})_{2}$.

Extensive work has been carried out on the decomposition kinetics of solid system. Multiple techniques were reported in literatures for determining the reaction mechanism and deducing kinetic parameters $^{[9-15]}$. Contrary to the homogeneous reaction, the mechanism and kinetics of solid decomposition will vary with many factors such as the particle size, the crystal form, and the reaction conditions. This phenomenon is mainly owing to the influence of heat transfer and mass transfer on the phase boundaries. Since that, although the dissociation of magnesium hydroxide has been widely studied, its mechanism and kinetic parameters reported in the literatures are not well consistent ${ }^{[16-17]}$. Halikia et al. ${ }^{[18]}$ has observed that the controlling mechanism of the thermal decomposition of magnesium hydroxide corresponds to the two dimensional nucleation and growth $\mathrm{A}_{2}$ in the temperatures above $400{ }^{\circ} \mathrm{C}$, while at lower temperature of $300{ }^{\circ} \mathrm{C}$ the mechanism corresponds to the reaction at phase boundaries Fl (random nucleation). However, this conclusion needs further supplements from other independent evidence.

Although opinions differ on its applicability and reliability for recurring to the theory and equations of isothermal method, non-isothermal method has been still widely used in studying the solid thermal decomposition. Master-plot method ${ }^{[9]}$ is a popularly used method of data treating for the non-isothermal kinetics analysis due to its high resolving power and being less influenced by experimental conditions ${ }^{[20-21]}$. In this paper, an improved Master-plot method with numerical regression and optimization algorithm was suggested and the thermal decomposition kinetic behavior of magnesium hydroxide was analyzed. The significant effect of water vapor on the decomposition process of magnesium hydroxide was discussed based on the experimental results.

\section{Decomposition kinetics}

The commonly used equation in the non-isothermal decomposition kinetics is presented as below

$$
\mathrm{d} \alpha / \mathrm{d} t=k f(\alpha)
$$

in which $\alpha$ is the decomposition extent and the kinetic function $f(\alpha)$ depends on the reaction mechanism and the rate controlling

Received:December 20, 2004; Revised :January 31, 2005. Correspondent: YUE, Lin-Hai(E-mail :ylh@ mail.hz.zj.cn; Tel:+86-571-87952403; Fax :+86-571-87951895) 
step. It has an alternate form as

$$
g(\alpha)=\int_{0}^{\alpha} \frac{\mathrm{d} \alpha}{f(\alpha)}
$$

The most commonly used expressions of $f(\alpha)$ and $g(\alpha)$ can be found in the literature ${ }^{[22]}$.

If we adapt the Arrhenius form for rate constant $k=A$. $\exp \left(-E_{\mathrm{a}} / R T\right)$ and assume a linear temperature rising during the decomposition with the heating rate $\beta, T=T_{0}+\beta t$, formula (2) can be transformed to

$$
g^{*}(\alpha)=\int_{T_{0}}^{T} \frac{A}{\beta} \mathrm{e}^{-E_{\mathrm{a}} / R T} \mathrm{~d} T
$$

Define another function $Z(\alpha)$ as

$$
Z(\alpha)=f(\alpha) g(\alpha)
$$

Also $Z(\alpha)$ can be transformed as

$$
Z^{*}(\alpha)=\frac{\mathrm{d} \alpha}{\mathrm{d} T} \mathrm{e}^{E_{\mathrm{a}} R T} \int_{T_{0}}^{T} \mathrm{e}^{-E_{\mathrm{a}} / R T} \mathrm{~d} T
$$

Equations (4) and (5) can be used to relate the experimental data with the theoretical values.

In order to improve the precision limited by the approximate formula and graphic fitting utilized in Master-plot method ${ }^{[23]}$, a more accurate numerical regression and optimization algorithm has been developed. Briefly, mechanism-free equations are firstly introduced to estimate the activation energy as a prerequisite for determining the reaction mechanism. After the reaction mechanism is deduced, the corresponding kinetic equations are then used to further confirm the kinetic parameters obtained previously. The steps of this algorithm can be shortly described as follows.

(1) Model-free method to estimate the activation energy of decomposition:

Firstly, Kissinger equation ${ }^{[24]}$, which is independent on the decomposition mechanism, is applied to estimate the activation energy

$$
\ln (A)=\ln \left(E_{\mathrm{a}} / R\right)-\ln \left(T_{\mathrm{p}}^{2} / \beta\right)+E_{\mathrm{a}} / R T_{\mathrm{p}}
$$

where $T_{\mathrm{p}}$ represents the peak temperature of a DTA curve. Changing heating rate $\beta$ and plotting $\left(\ln \left(T_{\mathrm{p}}^{2} / \beta\right)\right)$ against $1 / T_{\mathrm{p}}$, the activation energy $E_{\mathrm{a}}$ could be derived from the line slope.

Since Kissinger equation uses the peak temperature to compute the activation energy that only represents the decomposition extent $\alpha$ around $50 \%$, so that the isoconversional method is further used to check the activation energy change over the whole decomposition extent range.

$$
\ln (\beta \mathrm{d} \alpha / \mathrm{d} T)=\ln (A f(\alpha))-E_{\mathrm{a}} / R T_{\alpha}
$$

here $T_{\alpha}$ is the temperature at which a given conversion $\alpha$ is reached at an experimental heating rate $\beta$ and $\mathrm{d} \alpha / \mathrm{d} T$ is the corresponding decomposition rate at this conversion. Then the activation energy $E_{\mathrm{a}}$ at this given $\alpha$ can be evaluated by plotting $\ln (\beta \mathrm{d} \alpha / \mathrm{d} T)$ against $1 / R T_{\alpha}$.

(2) An improved Master-plot method which is more accurate and less influenced by experimental conditions, is developed to determine the reaction mechanism. Here, a numerical integral is applied instead of the approximate formula to compute the experimental value of function $Z^{*}(\alpha)$ at a certain $\alpha$ by substituting the experimental $\alpha-T$ data and the as obtained activation energy $E_{\mathrm{a}}$ into equation (5). Meanwhile, the theoretical value of $Z(\alpha)$ can be easily calculated for a pair of chosen mechanism functions $f(\alpha)$ and $g(\alpha)$. Then an objective function is defined as the sum of square residual errors.

$$
\Delta=\sum_{\alpha}\left(Z(\alpha)-Z^{*}(\alpha)\right)^{2}
$$

Try all possible mechanism function pair $f(\alpha)$ and $g(\alpha)$, (we use total 29 functions) ${ }^{[22]}$, and the one that minimizes $\Delta$ value represents the most suitable mechanism. In addition, for more direct observation, $Z^{*}(\alpha)$ can also be plotted together with a series of standard $Z(\alpha)$ curves to see how well $Z^{*}(\alpha)$ fit the corresponding mechanism curve as in the normal Master-plot case.

(3) Afterward, another objective function is set up as

$$
\Delta=\sum_{\alpha}\left(g(\alpha)-g^{*}(\alpha)\right)^{2}
$$

here $g(\alpha)$ is the as determined mechanism function and $g^{*}(\alpha)$ is an integral formatted as equation (3) with two unknown variables $E_{\mathrm{a}}$ and $A$.

A standard two-variable optimum searching is carried out to get the final kinetic parameters $A$ and $E_{\mathrm{a}}$ which make the $\Delta$ value minimum. In this optimum searching process, the $E_{\text {a }}$ value estimated previously in step 1 can be used as a good initial trial.

\section{Experiments}

$\mathrm{Ca}(\mathrm{OH})_{2}$ slurry was dripped into $4 \mathrm{~mol} \cdot \mathrm{L}^{-1} \mathrm{MgCl}_{2}$ with a rate of $20 \mathrm{drops} / \mathrm{min}$ at room temperature until the $\mathrm{pH}$ value of the solution was at 10 11. Then the solution was heated up to $60{ }^{\circ} \mathrm{C}$ with continual stirring for $3 \mathrm{~h}$. The precipitate was filtrated, washed with deionized water until the $\mathrm{pH}$ value of the filtrate equals to about 7 , and desiccated at $110{ }^{\circ} \mathrm{C}$ to constant weight and then sifted through 120 mesh. The magnesium hydroxide obtained was referred as sample 1090.

Titration method was used to determine the purity of the product.

X-ray powder diffraction patterns were obtained at room temperature by a Philips diffractometer model X Pert MPD using $\mathrm{Cu} K_{\alpha}$ radiation. The accelerating voltage was $40 \mathrm{kV}$ with $45 \mathrm{~mA}$ flux at a scanning rate of $1\left({ }^{\circ}\right) \cdot \mathrm{min}^{-1}$ and scanning step $0.02^{\circ}$.

The general TG-DTA curves were determined by a WCT-1 analyzer at a heating rate of $10{ }^{\circ} \mathrm{C} \cdot \mathrm{min}^{-1}$ in air atmosphere with the flow rate of $20 \sim 30 \mathrm{~mL} \cdot \mathrm{min}^{-1}$. The non-isothermal kinetic experiments were carried out at the heating rates of $5,10,15,20$ 
Table 1 Purity analysis of sample 1090

\begin{tabular}{ccccc}
\hline Sample & $\mathrm{Ca}^{2+}(\%)$ & $\mathrm{Mg}^{2+}(\%)$ (theory value) & $\mathrm{OH}^{-}(\%)$ & Purity $(\%)$ \\
\hline 1090 & 0.55 & $41.42(41.67)$ & 55.88 & 99.40
\end{tabular}

${ }^{\circ} \mathrm{C} \cdot \mathrm{min}^{-1}$ in both dried and humid air atmosphere. The humid air was obtained by saturating dried air with water vapor at $30{ }^{\circ} \mathrm{C}$.

\section{Results and discussion}

\subsection{Purity analysis and XRD analysis}

The result of the purity analysis of sample 1090 by chemical titration is listed in Table 1.

Fig.1 is the X-ray diffraction pattern. It shows that the intensity and position of the diffraction peaks are in good agreement with the standard spectrum of the crystalline $\mathrm{Mg}(\mathrm{OH})_{2}$ according to JCPDS(International Centre for Diffraction Data, data No.07-0239). It proves that sample 1090 was crystalline $\mathrm{Mg}(\mathrm{OH})_{2}$ with high purity.

\subsection{Decomposition mechanism and kinetic parameters}

The general TG-DTA curves at different heating rates of sample 1090 are showed as Fig. 2.

For each heating rate of the sample, $\ln \left(T_{\mathrm{p}}^{2} / \beta\right)$ is plotted against $1 / T_{\mathrm{p}}$ (Eq.(6)). Fig.3a shows a straight line which fits the data points best. The corresponding activation energy $E_{\mathrm{a}}$ obtained from the line slope is $146.1 \mathrm{~kJ} \cdot \mathrm{mol}^{-1}$.

In order to verify the variation of the activation energy dep ending on the decomposition extent, the isoconversional method (as formula 7) is additionally introduced to compute the activation energy as a function of decomposition extent $\alpha$ and Fig.4 shows the obtained results. It is found that the value of $E_{\text {a }}$ only changes slightly in most of the decomposition process except at the beginning stage. Its value keeps holding around $145 \mathrm{~kJ}$. $\mathrm{mol}^{-1}$ in whole the region of $\alpha$ greater than 0.1. Therefore this activation energy value is adapted to further determine the decomposition mechanism.

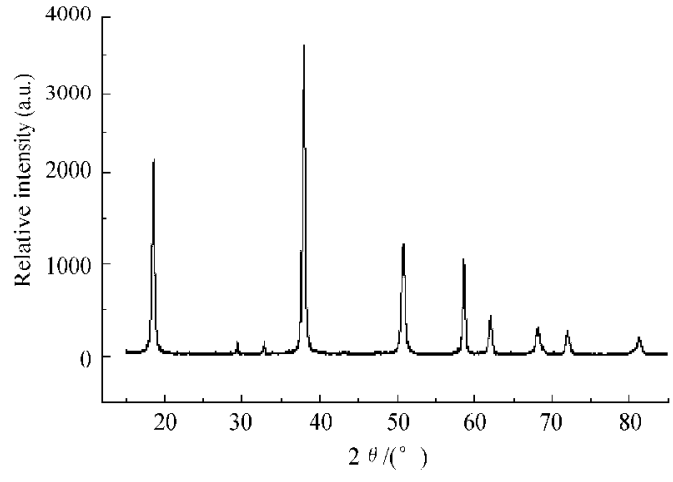

Fig.1 XRD pattern of sample 1090

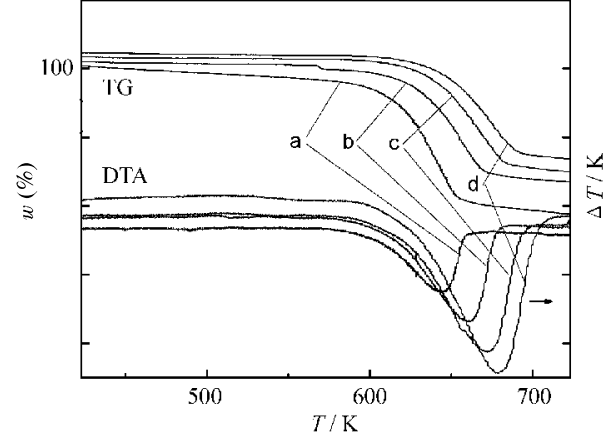

Fig.2 TG-DTA curves of sample 1090 at different heating rates

$\beta / \mathrm{K} \cdot \mathrm{min}^{-1}$ : (a) 5 ; (b) 10 ; (c) 15 ; (d) 20

As described in section 2, a numerical optimization method was used to search the best fitting decomposition mechanism. The results are as follows. For the heating rate of $5 \mathrm{~K} \cdot \mathrm{min}^{-1}$, it seems the nucleation and growth mechanism $\mathrm{A}_{2}$ fits the experimental data best while mechanism $A_{1.5}$ fits the experimental data at the heating rates of 15 and $20 \mathrm{~K} \cdot \mathrm{min}^{-1}$. However, in the case of $10 \mathrm{~K} \cdot \mathrm{min}^{-1}$ heating rate the experimental data lie between the two mechanism models. Fig. 5 plotted the experimental data together with the possible mechanism curves. It clearly shows that as the heating rate increasing, the decomposition mechanism changes from $A_{2}$ to $A_{1.5}$ but this change is less obvious at high $\alpha$ value.

For further confirmation of the reaction mechanism, Coats and Redfern equation ${ }^{[25]}$ is introduced as a test.

$$
\lg \left(g(\alpha) / T^{2}\right)=\lg \left(A R / E_{\mathrm{a}} \beta\right)-E_{\mathrm{a}} / 2.303 R T
$$

Using the experimental data of sample 1090 at each heating rate, plot $\lg \left(g(\alpha) / T^{2}\right)$ against $1 / T$. It is found that the curves corresponding to as previously deduced mechanisms at heating rates of $5,15,20 \mathrm{~K} \cdot \mathrm{min}^{-1}$ are closer to a straight line than other mechanisms. However, as for the case of $10 \mathrm{~K} \cdot \mathrm{min}^{-1}$ heating rate in which the mechanism lies between $\mathrm{A}_{2}$ and $\mathrm{A}_{1.5}$, the curve corresponds to either mechanism is not straight.

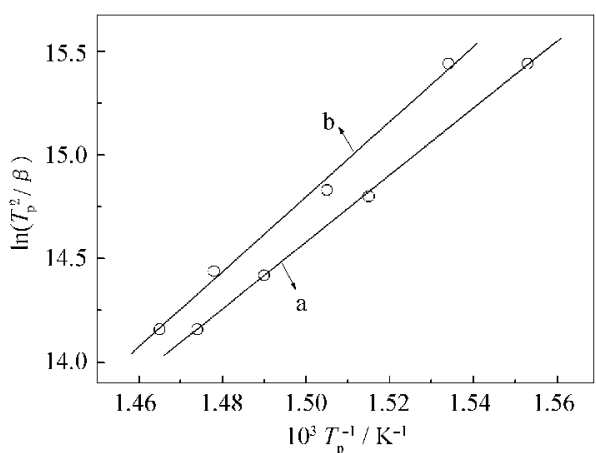

Fig.3 $\ln \left(T_{\mathrm{p}}{ }^{2} / \beta\right) v s 1 / T_{\mathrm{p}}$ plot of (a) sample 1090 and (b) sample 1090 under humid air of $30^{\circ} \mathrm{C}$ 


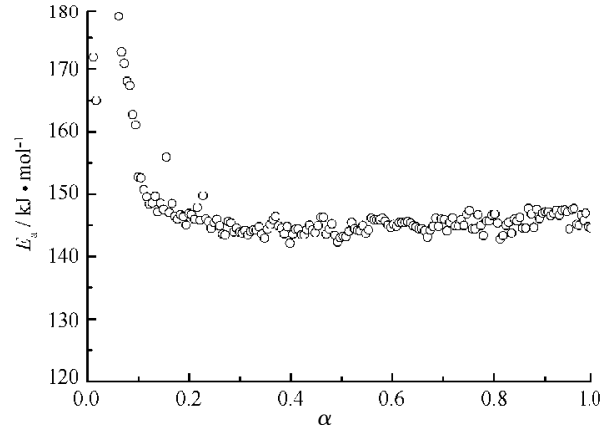

Fig.4 Dependence of the activation energy on decomposition extent determined by isoconversional method

Finally, optimum searching mentioned in section 2 was carried out to accurately determine the kinetic parameters for each heating rate. The obtained values of $E_{\mathrm{a}}$ are listed in Table 2 .

\subsection{The effect of water vapor on the kinetic mechanism}

To explain why the decomposition mechanism changes from $A_{2}$ to $A_{1.5}$ model as the heating rate rising, humid air was introduced to investigate the possible influence. As showed in Fig.6, there is obvious difference on the TG-DTA curve in the case of dry or wet air atmosphere. It reveals that $\mathrm{Mg}(\mathrm{OH})_{2}$ has higher decomposition temperature in humid air atmosphere. To confirm the influence of water vapor, a non-isothermal decomposition of the same sample but under humid air atmosphere was carried out. The experimental curves are shown in Fig.7.

The data analysis is as the same as previous. The plot of $\ln \left(T_{\mathrm{p}}^{2} / \beta\right)$ against $1 / T_{\mathrm{p}}$, as showed in Fig.3b, gives the activation energy $E_{\mathrm{a}}$ of $152 \mathrm{~kJ} \cdot \mathrm{mol}^{-1}$. Results of the mechanism fitting are graphically illustrated in Fig.8. It differs a little from the dry atmo sphere case. The decomposition mechanism still remains $\mathrm{A}_{1.5}$ at heating rates of 15 and $20 \mathrm{~K} \cdot \mathrm{min}^{-1}$ but has changed at lower heating rates. Namely, the experimental data almost fits

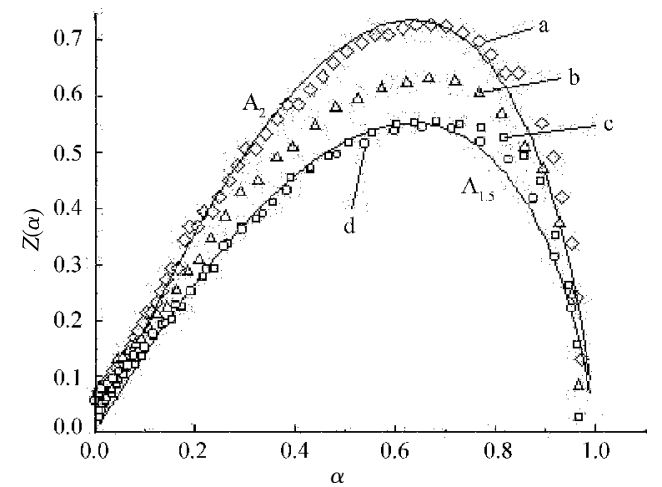

Fig.5 Experimental curves of $\mathbf{Z}(\alpha)$ at different heating rates $\beta / \mathrm{K} \cdot \min ^{-1}$ : (a) $5(\diamond)$; (b) $10(\Delta)$; (c) 15 ( $\square$ ); (d) 20 (o)
Table 2 Activition energy of sample 1090

\begin{tabular}{ccc}
\hline Heating rate $\left(\mathrm{K} \mathrm{min}^{-1}\right)$ & Possible mechanism & $E_{\mathrm{a}} / \mathrm{kJ} \cdot \mathrm{mol}^{-1}$ \\
\hline 5 & $\mathrm{~A}_{2}$ & 147.5 \\
10 & $\mathrm{~A}_{2}, \mathrm{~A}_{1.5}$ & $126.5,172.2\left(\bar{E}_{\mathrm{a}}=149.4\right)$ \\
15 & $\mathrm{~A}_{1.5}$ & 150.7 \\
20 & $\mathrm{~A}_{1.5}$ & 149.9 \\
\hline
\end{tabular}

$\mathrm{A}_{1.5}$ mechanism at a heating rate of $10 \mathrm{~K} \cdot \mathrm{min}^{-1}$ but lies between $\mathrm{A}_{2}$ and $\mathrm{A}_{1.5}$ mechanisms at heating rate of $5 \mathrm{~K} \cdot \mathrm{min}^{-1}$. Thus, the thermal decomposition mechanism of $\mathrm{Mg}(\mathrm{OH})_{2}$ seems closer to $\mathrm{A}_{1.5}$ model (growth of nuclei model) under a humid air atmosphere.

\subsection{Discussion}

$\mathrm{Ortega}^{[26]}$ previously reported that for an overall reaction comprising several independent competed elementary reactions, its essence could be deduced by changing the heating rate $\beta$. The thermal decomposition of magnesium hydroxide is a complex overall reaction containing several elementary reactions which compete each other. It is supposed changing the heating rate $\beta$ may alter the rate of each elementary reaction differently so that to display an apparent mechanism changing.

Heda et al. ${ }^{[27]}$ has reported that, for the decomposition of sodium bicarbonate under an atmosphere of carbon dioxide, the $\mathrm{A}_{1.5}$ Avrami-Erofeev equation showed better regression factors and the activation energy was higher than that observed under dry nitrogen. They suggested that the presence of $\mathrm{CO}_{2}$, which was also liberated during the decomposition process, made it difficult for the reaction to proceed in the forwa rd direction. Similarly in our experiments a more conceivable explanation is suggested that the water molecule produced in the decomposition has a significant effect on the mechanism apparently. The accessional experiment under wet atmosphere has proved the im-

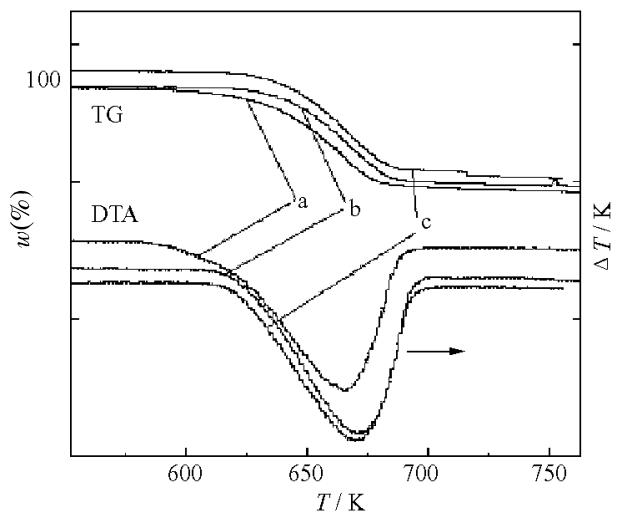

Fig.6 TG-DTA curves of sample 1090 in dried air (a) and in humid air at different temperatures of (b) $30{ }^{\circ} \mathrm{C}$ and (c) $70{ }^{\circ} \mathrm{C}$ 


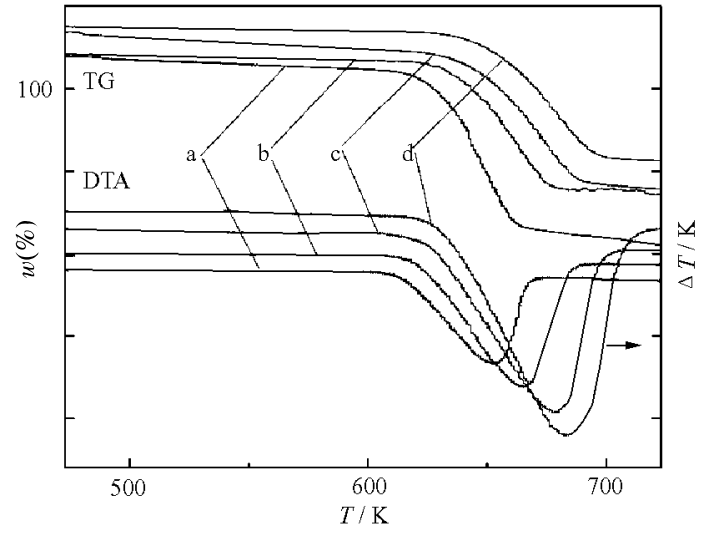

Fig.7 TG-DTA curves of different heating rates of sample 1090 under humid air of $30^{\circ} \mathrm{C}$ $\beta / \mathrm{K} \cdot \mathrm{min}^{-1}$ : (a) 5 ; (b) 10 ; (c) 15 ; (d) 20

portant effect of water vapor on the decomposition mechanism. It suggests that the apparent mechanism of the thermal decomposition of $\mathrm{Mg}(\mathrm{OH})_{2}$ changes from $\mathrm{A}_{2}$ to near $\mathrm{A}_{1.5}$ model gradually as the partial water vapor pressure ascends.

The Avrami-Erofeev equation ${ }^{[28]}$ is the kinetic expression appropriate to random nucleation and the nuclei growth process

$$
[-\ln (1-\alpha)]^{1 / n}=k t
$$

where $n$ is usually considered as the reaction order and $k$ is the rate constant. Masuda et al. ${ }^{[29]}$ has deemed that parameter $n$ depends on the nucleation rate, the geometry of the nuclei, and the growth mechanism such as either diffusion-controlled or phase-boundary-controlled. The values of $n$ in Avrami-Erofeev kinetic family should be $1.5,2,2.5,3$, respectively. Ortega et al. ${ }^{[30]}$ summarized nuclei growth conditions and pointed out the relationship between nuclei growth and various boundary conditions as follows. If the nucleation rate is assumed to be constant and the nuclei growth is controlled by the diffusion of migrating species, the $\mathrm{A}_{1.5}(\alpha)$ equation can be derived when the nuclei grow one-dimensionally while $\mathrm{A}_{2}(\alpha)$ equation will stand as the nuclei grow two-dimensionally. So it seems in the case of magnesium hydroxide decomposition, relatively high water vapor pressure can retard the reaction and may possibly turn the random nucleation process from a two-dimensional form to one-dimensional. This may be a reasonable explanation for the mechanism change with the rising of the heating rate in non-isothermal decomposition of $\mathrm{Mg}(\mathrm{OH})_{2}$. It also means that the mechanism deduced at lower heating rate, $A_{2}$, is more intrinsic for the thermal decomposition of magnesium hydroxide.

\section{Conclusions}

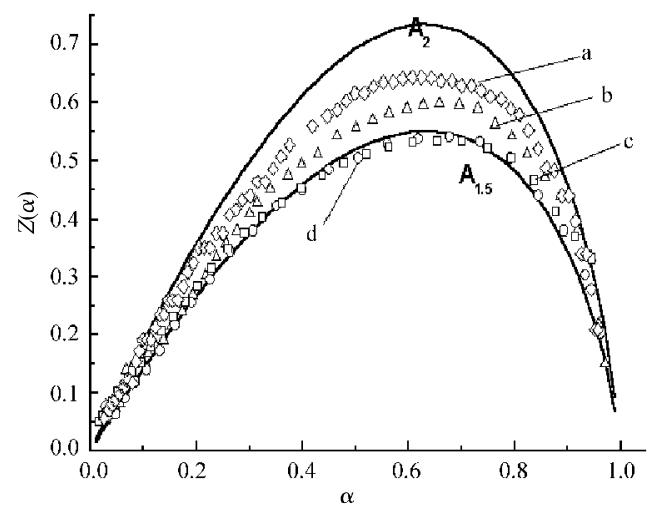

Fig.8 Experimental curves of $Z(\alpha)$ at different heating rates under humid air of $30{ }^{\circ} \mathrm{C}$ $\beta / \mathrm{K} \cdot \mathrm{min}^{-1}$ :(a) $5(\diamond)$; (b) $10(\Delta)$; (c) 15 ( $\square$ ); (d) 20 (o)

(1) Non-isothermal kinetic analysis substantiates that magnesium hydroxide dissociates according to the nuclei formation and growth mechanism A, which is in accordance with some of the literature reports ${ }^{[18]}$. However, the mechanism changes from $\mathrm{A}_{2}$ to $\mathrm{A}_{1.5}$ with the rising of heating rate from $5 \mathrm{~K} \cdot \mathrm{min}^{-1}$ to 20 $\mathrm{K} \cdot \mathrm{min}^{-1}$. This phenomenon is first reported as to the authors' knowledge.

(2) The activation energy obtained from mechanism-free equation is consistent with that obtained from mechanism equation. It manifests the validity of both the reaction mechanism and the activation energy value. The activation energy of the magnesium hydroxide obtained from our experiments is approximately $148 \mathrm{~kJ} \cdot \mathrm{mol}^{-1}$ and the value is in accordance with some of previous reports.

(3) Effect of water vapor on the thermal decomposition of $\mathrm{Mg}(\mathrm{OH})_{2}$ was investigated by carrying out the kinetic experiments under a humid air atmosphere. It is found that the mechanism of the thermal decomposition of $\mathrm{Mg}(\mathrm{OH})_{2}$ seems closer to $\mathrm{A}_{15}$ model in the humid air condition than that in dried air atmosphere at same heating rate. It is supposed that the higher partial water vapor pressure may retard the decomposition process and hence alter the apparent mechanism. From above discussion, it seems the mechanism deduced at lower heating rate is more intrinsic.

\section{References}

1 Maruo Calcium, K.K. Slurry or powder composition, used for addition to foodstuff, contains magnesium hydroxide and polyglycerine fatty acid ester as emulsion stabilizer. JP2001333735-A; JP3504217-B2. 2001

2 Kunimine Kogyo, K.K. Water treating agent for industrial waste 
water comprising clay ore, sodium salt and/or sodium (hydr)oxide and magnesium salt and/or magnesium (hydr)oxide. JP59228906A; JP88033405-B. 1999

3 Kim, S. J. Polymer Science Part B:Polymer Phys., 2003, 41(9): 936-944

4 Shin, H.S.; Lee, S.M. Environ. Technol., 1998, 19: 283

5 Plastics, Additives and Compounding, 2000, 2: 24

6 Rothon, R.N.; Hornsby, P.R. Polymer Degradation and Stability, 1996, 54 : 383

7 Weber, M. Functional effect fillers 2000. Berlin, Germany : Intrtech Conf., 2000: 9

8 Titelman, G.I.; Gonen, Y.; Kedar, Y.; Bron, S. Polymer Degradation and Stability, 2002, $77: 345$

9 Doyle, C.D. J. Appl. Polym. Sci., 1961, 5: 285

10 Zsako, J. J. Phys. Chem., 1968, 72: 2406

11 Rajeswara, R.T. Chem. Eng. Technol., 1996, 19: 373

12 Criado, J.M.; Malek, J.; Ortega, A. Thermochim. Acta, 1989, 147 : 377

13 Malek, J. Thermochim. Acta, 1992, 200: 257

14 Gadalla, A.M. Thermochim. Acta, 1985, 95: 179

15 Gadalla, A.M. Thermochim. Acta, 1984, 74: 255

16 Gregg, S.J.; Razouk, R.I. J. Chem. Soc., 1949: S36

17 Turner, R.C.; Hoffman,I.; Chen, D. Canadium J. Chemstry, 1963,

$$
\text { 41: } 243
$$

18 Halikia, I.; Neou-Syngouna, P.; Kolitsa, D. Thermochim. Acta, 1998, 320: 75

19 Perez-Maqueda, L.A.; Ortega, A.; Criado, J.M. Thermochim. Acta, 1996, 277: 165

20 Lu, Z. R. Chinese J. Inorg. Chem., 1998, 14(2): 119 [陆振荣. 无 机化学学报(Wuji Hиахие Xиebao), 1998, 14(2): 119]

21 Yue, L.H.; Shui, M.; Xu, Z.D. Cheinese J. Inorg. Chem., 1999, 15 (2): 225 [岳林海, 水 永, 徐铸德. 无机化学学报(Wuji Huaxue Хиеьао), 1999, 15(2): 225]

22 Dollimore, D.; Tong, P.; Alexander, K. Thermochim. Acta, 1996, 282/283: 13

23 Malek, J. Thermochim. Acta, 1992, 200 : 257

24 Kissinger, H.E. J. Res. Nat. Bur. Stand., 1956, 57: 712

25 Coats, A.W.; Redfern, J.P. Nature, 1964, 201: 68

26 Ortega, A. Thermochim. Acta, 1996, 284 : 379

27 Heda, P.K.; Dollimore, D.; Alexander, K.S.; Chen, D.; Law, E.; Bicknell, P. Thermochim. Acta, 1995, 255: 255

28 Herrera, H. Thermochim. Acta, 1997, 293 : 39

29 Masuda, Y.; Shirotori, S.; Minagawa, K.; Gallagher, P.K.; Zhong, Z. Thermochim. Acta, 1996, 282/283: 43

30 Ortega, A.; Maqueda, L.P.; Criado, J.M. Thermochim. Acta, 1995, 254: 147

\title{
$\operatorname{Mg}(\mathrm{OH})_{2}$ 热分解反应的非等温动力学研究
}

\author{
岳林海 金达莱 吕德义 ${ }^{1} \quad$ 徐铸德 $^{-1}$ \\ (浙江大学化学系, 杭州 310027； 1浙江工业大学化学工程与材料科学学院, 杭州 310014)
}

摘要 用非等温动力学方法对氢氧化镁的热分解动力学进行了研究. 分解反应机理符合晶核形成及生长机 理 $\mathrm{A}$, 且随着升温速率的升高, 机理由 $\mathrm{A}_{2}$ 转变为 $\mathrm{A}_{1.5}$. 根据 Kissinger 非机理方程计算和数值回归方法验证 所得的分解反应活化能结果相互印证, 约为 $148 \mathrm{~kJ} \cdot \mathrm{mol}^{-1}$. 进一步研究发现, 水蒸气的存在对氢氧化镁热分 解反应具有非常明显的影响, 可能是其动力学机理随升温速率升高而改变的主要影响因素.

关键词: 氢氧化镁, 热分解, 非等温动力学

中图分类号： O642，O643 